\title{
AN EXPERIMENTAL STUDY OF THE WATER MOLECULES IN NATROLITE
}

\author{
S. el D. HAMAD
}

\begin{abstract}
HAMAD, S. el D. 1977: An experimental study of the water molecules in natrolite. Bull. Geol. Soc. Finland 49: 1-6.

A thermogravimetric balance was used to study the conditions of water molecules in natrolite. Dehydration under vacuum conditions was completed in a single stage at $189^{\circ} \mathrm{C}$. A series of isothermal experiments carried out on dehydrated natrolite in the range $150-210^{\circ} \mathrm{C}$ and with varying water vapour pressures gave a heat of hydration of $15.690 \mathrm{Kcal}$. mole ${ }^{-1} \mathrm{H}_{2} \mathrm{O}$. Infrared absorbtion bands of $\mathrm{H}_{2} \mathrm{O}$ in the mineral were studied before and after thermal treatment.

The results obtained showed that natrolite is not a definite hydrate and that the water molecules within its channels are weakly bound to the silicate framework which was not fractured or strained by excessive thermal treatment.
\end{abstract}

S. el D. Hamad, Department of Geology, University of Khartoum, Khartoum, Sudan.

\section{Introduction}

The presence of water molecules in the mineral natrolite has attracted the attention of many research workers. Hey (1932b and 1935) and Milligan and Weiser (1937) believe that these water molecules occupy definite lattice positions, whereas, Peng (1955) considers that the two water molecules occupy equivalent lattice positions by merely filling the channels that penetrate the three - dimensional framework. Other workers, namely, Mayer, Manuilova and Varshal (1964), and Saha (1961) are of the opinion that under certain physiochemical conditions, natrolite decomposes to analcite.
The aim of the present work was to perform some dehydraton - hydration experiments on this mineral in an attempt to obtain data that can throw more light on the state of its water molecules.

The first step was to obtain with the aid of the technique of thermogravimetry (Hamad 1975) the dehydration curve of the mineral in an experiment performed under vacuum conditions and as a function of slowly rising temperature. This was followed by a series of isothermal experiments on dehydrated natrolite in the temperature range 150 $210^{\circ} \mathrm{C}$ under vacuum conditions and as a function of imposed water vapour pressure. Finally, infrared spectroscopy was used to 
study the effect of thermal treatment on the position of the absorption bands of the water molecules.

\section{Specimen}

A specimen of natrolite (H.NAT) was kindly supplied by Dr. S. O. Agrell of the Department of Mineralogy and Petrology, Cambridge. Wet chemical analysis of the mineral (analysed by S. el D. Hamad) and determination of the physical properties gave: $\mathrm{SiO}_{2} 47.28 \%, \mathrm{Al}_{2} \mathrm{O}_{3} 27.47 \%, \quad \mathrm{Na}_{2} \mathrm{O} 16.63 \%$, $\mathrm{K}_{2} \mathrm{O} \quad 0.09 \%, \mathrm{H}_{2} \mathrm{O} \quad 9.42 \%$, Total $100.89, \alpha=$ $1.479, \beta=1.480, \gamma=1.490$, sp.gr. $=2.233$. The calculated formula is: Si 2.96, Al 2.02, $\mathrm{Na} 2.01, \mathrm{~K} 0.007, \mathrm{H}_{2} \mathrm{O}$ 1.97. This composition is very close to the ideal formula $\mathrm{Na}_{2} \mathrm{Al}_{2}$ $\mathrm{Si}_{3} \mathrm{O}_{12} \cdot 2 \mathrm{H}_{2} \mathrm{O}$ for natrolite.

\section{Dehydration of natrolite}

Method. A portion weighing $200 \mathrm{mg}$ of a natrolite sample was introduced into the thermogravimetric balance. It was outgassed at room temperature and over $\mathrm{P}_{2} \mathrm{O}_{5}$ for approximately two hours. The temperature was then slowly raised. Each rise in temperature needed from 7 to 10 minutes to be established; a further 5 minutes were allowed before the balance reading was recorded. The amount of weight loss was recorded every 5 minutes for each established temperature until equilibrium was reached.

Results. Plots of Weight loss as a function of slowly rising temperature are shown in Fig. 1. It is clear from the isobar that dehydration began at $\simeq 110^{\circ} \mathrm{C}$, but the greater amount of water was lost at $189^{\circ} \mathrm{C}$. There was no notable slowness in dehydration.

\section{Absorption isotherms of dehydrated natrolite}

Method. A fresh portion of natrolite weighing $200 \mathrm{mg}$ was first dehydrated under va-

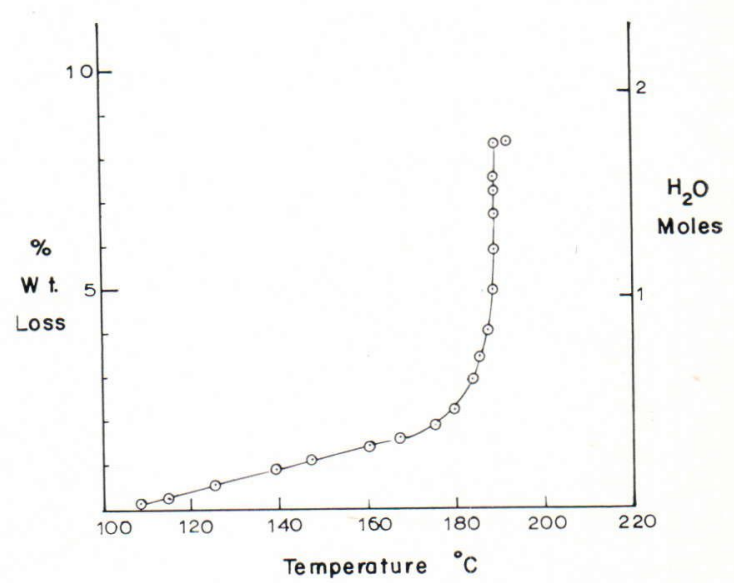

Fig. 1. Dehydration curve for Natrolite under vacuum conditions.

cuum conditions and over $\mathrm{P}_{2} \mathrm{O}_{5}$ at $190^{\circ} \mathrm{C}$. The sample was then submitted to a series of isothermal experiments carried out as a function of imposed water vapour pressures. The temperatures selected were in the range $150-210^{\circ} \mathrm{C}$; each desired temperature was brought to a fairly constant value with a slight variation of $\pm 0.5^{\circ} \mathrm{C}$. Water vapour was imposed at the rate of $1 \mathrm{~mm} \mathrm{Hg}$. During the early stages of the reaction, adsorption was so rapid that equilibrium was established in a period of approximately one minute. But as the reaction proceeded this period rose to 5-7 minutes. Each time equilibrium was reached, a further three minutes were allowed before the balance readings were recorded. When final equilibrium was attained at the end of the first experiment, the secimen and the manometer were outgassed over fresh $\mathrm{P}_{2} \mathrm{O}_{5}$ until desorption was complete. The temperature was brought to the next desired value and a similar adsorption experiment was conducted. Data were obtained at temperatures:

$207^{\circ} \mathrm{C}, 192^{\circ} \mathrm{C}, 180^{\circ} \mathrm{C}, 172^{\circ} \mathrm{C}$ and $153^{\circ} \mathrm{C}$.

Results. The adsorption isotherms illustrating the extent of water vapour absorbed by the dehydrated natrolite specimen over a 


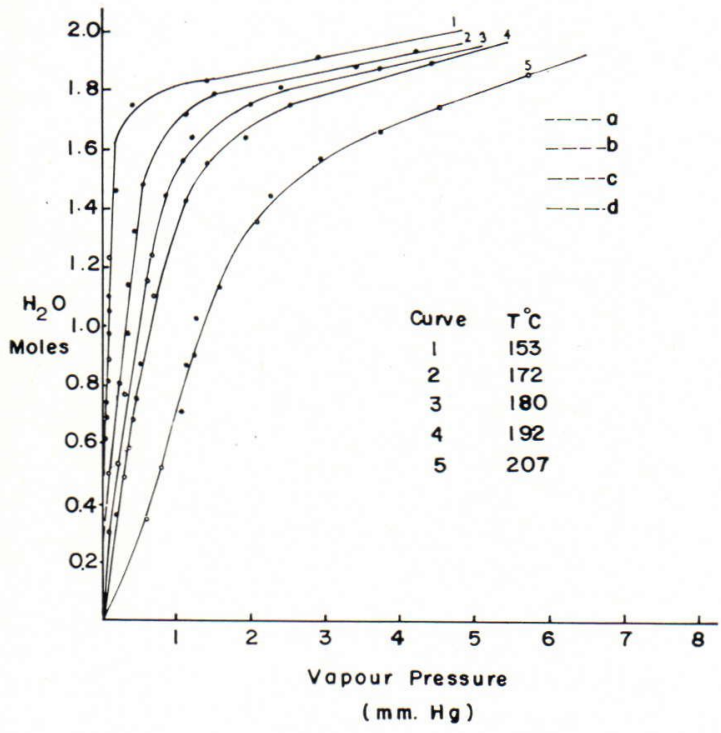

Fig. 2. Absorption isotherms of dehydrated natrolite showing the extent of hydration and the corresponding equilibrium vapour pressures.

range of established equilibrium vapour pressures at the specified temperatures are shown in Fig. 2. Equilibrium vapour pressures at certain positions on the isotherms »along the dotted lines a, b, c, d» are given in Table 1

Table 1. Data from Fig. 2.

\begin{tabular}{|c|c|c|c|c|}
\hline \multirow{2}{*}{$\begin{array}{c}\text { Tempera- } \\
\text { ture }{ }^{\circ} \mathrm{C}\end{array}$} & \multicolumn{4}{|c|}{ Vapour pressure $\mathrm{mm} \mathrm{Hg}$} \\
\hline & a & $\mathrm{b}$ & c & $\mathrm{d}$ \\
\hline 207 & 4.00 & 3.08 & 2.46 & 2.10 \\
\hline 192 & 2.12 & 1.58 & 1.27 & 1.09 \\
\hline 180 & 1.48 & 1.10 & 0.92 & 0.80 \\
\hline 172 & 1.03 & 9.73 & 0.55 & 0.48 \\
\hline 153 & 0.30 & 0.20 & 0.17 & 0.16 \\
\hline
\end{tabular}

using the integrated form of van't Hoff equation

$$
\text { 1n } \frac{\mathrm{P}_{2}}{\mathrm{P}_{1}}=-\frac{\triangle \mathrm{H}}{\mathrm{R}}\left(\frac{1}{\mathrm{~T}_{2}}-\frac{1}{\mathrm{~T}_{1}}\right)
$$

values of $1 \mathrm{n} \mathrm{P}$ were plotted against $\left(\mathrm{T}^{\circ} \mathrm{K}\right)^{-1}$ for each group of equilibrium pressures shown in Table 1. The slopes of the straight

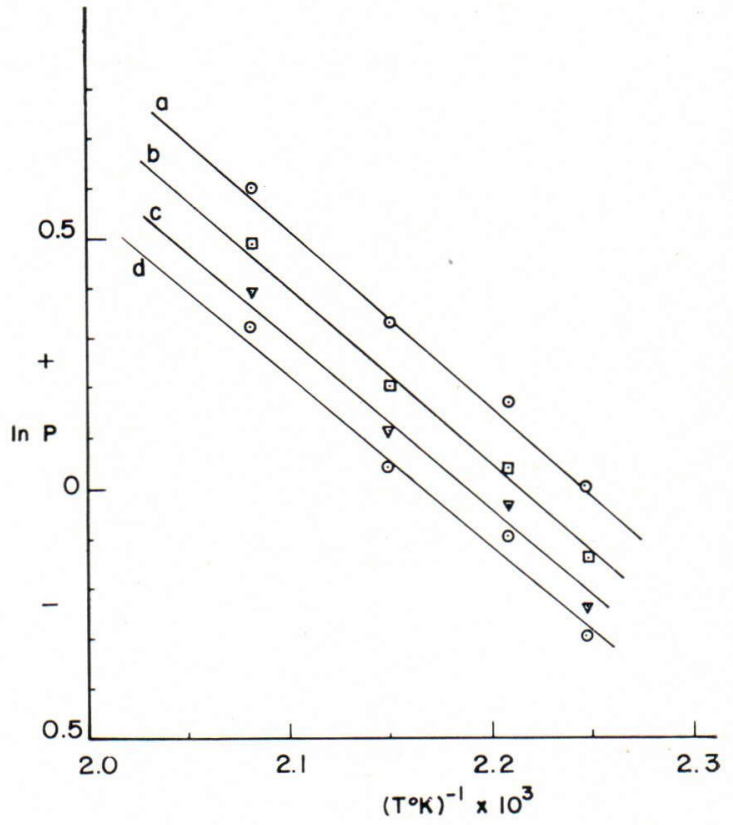

Fig. 3. Temperature dependence of the equilibrium vapour pressures of natrolite. Each straight line represents the vapour pressures at positions running through the dotted line, (see Fig. 2).

lines obtained from these plots (Fig. 3) are almost equal; an average of $3.424 \times 10^{3}$ was obtained.

From this value of the slope, the heat of adsorption in the temperature range studied was calculated:

$\triangle \mathrm{H}$

$=3.425 \times 10^{3} \times 2.3026 \times 1.986$

$=15.690 \mathrm{Kcal}$. mole ${ }^{-1} \cdot \mathrm{H}_{2} \mathrm{O}$

\section{Infrared absorption bands of water in natrolite}

Methods and results. The infrared spectra covering the frequency $4000-1500 \mathrm{~cm}^{-1}$ reproduced in Fig. 4 show the absorption bands of water in samples of natrolite both before and after adsorption-desorption. These spectra were measured in a Perkin-Elmer 337 spectrophotometer using the $\mathrm{KBr}$ pellet technique in which portions of approximately 


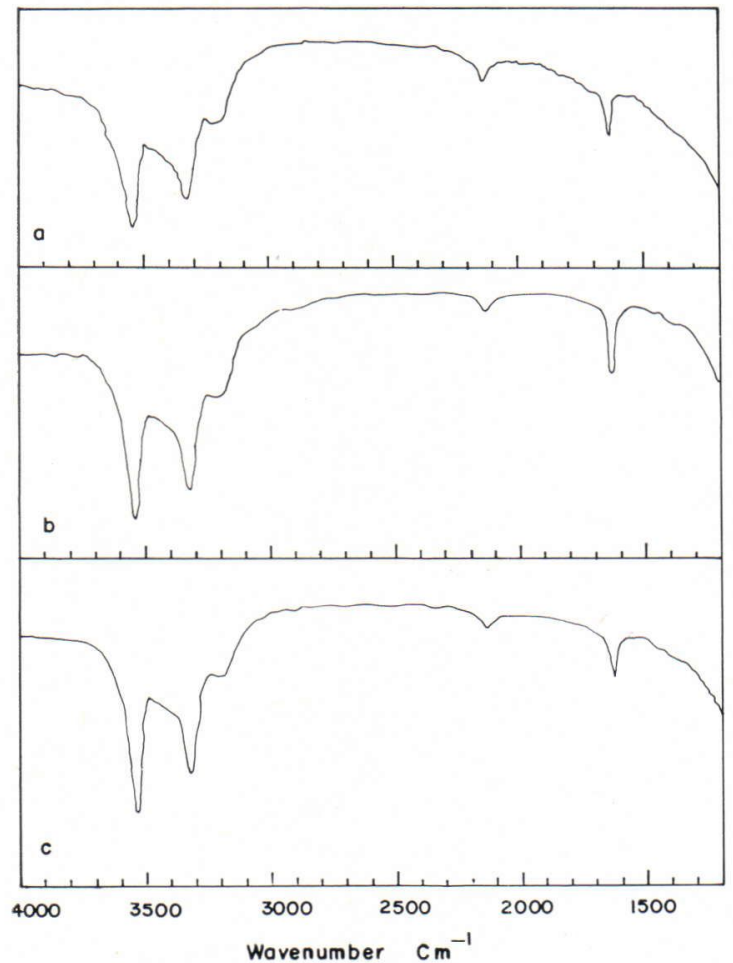

Fig. 4. Infrared absorption bands of water molecules in (a) original untreated natrolite, (b) residue recovered from isothermal experiments (c) natrolite heated at $190^{\circ} \mathrm{C}$ over $\mathrm{P}_{2} \mathrm{O}_{5}$ and reheated in the steel die prior to scanning.

$1 \mathrm{mg}$ of finely ground sample were mixed with $200 \mathrm{mg}$ of $\mathrm{KBr}$. Spectrum (a) is that of the original untreated specimen of natrolite. Spectrum (b) is that of the residue recovered at the end of the isothermal experiments outlined above. Spectrum (c) is that of fresh sample of natrolite dehydrated first under vacuum conditions and over $\mathrm{P}_{2} \mathrm{O}_{5}$ at $190^{\circ} \mathrm{C}$. While still hot, an appropriate portion was mixed with $\mathrm{KBr}$ and transferred to the steel die. It was reheated for a further period of two hours at $120^{\circ} \mathrm{C}$ before the disc was pressed and scanned immediately.

Inspite of the heating of the specimen of spectrum (c) the absorption bands were identical in both position and configuration to those of the untreated specimen, spectrum (a), and to the specimen subjected to excessive dehydration - hydration, spectrum (b). This indicates the rate of the adsorption process when the specimen was exposed to the ambient atmosphere during scanning.

Interpretation. Fox and Martin (1940), Serratosa and Bradley (1958) and Farmer (1964) showed that an unassociated water molecule absorbs infrared radiation at a frequency near $3700 \mathrm{~cm}^{-1}$ which corresponds to an $\mathrm{O}-\mathrm{H}$ stretching vibration. Under the influence of hydrogen bonding this frequency is displaced to a lower value, the amount of displacement being a measure of the strength of the hydrogen bond. $\mathrm{H}_{2} \mathrm{O}$ can also be identified by two other absorption bands: one near frequency $1600 \mathrm{~cm}^{-1}$, attributed to the bending vibrational mode of $\mathrm{H}-\mathrm{O}-\mathrm{H}$, and the other near $2100 \mathrm{~cm}^{-1}$, attributed to associated water molecules.

In the spectra of the three specimens of natrolite shown in Fig. 4, the $\mathrm{O}-\mathrm{H}$ stretching vibrational mode is resolved into two components at frequencies less than that of free water: $3540 \mathrm{~cm}^{-1}$ and $3320 \mathrm{~cm}^{-1}$. This shift in the position of the frequency indicates that a certain degree of hydrogen bonding occurs in the structure of the mineral. Moreover, the break up of the band into two components may be the result of coupling among the equivalent molecular groups in the structure (Mitra, 1962; Adler, 1965). On the other hand, the bending vibrational mode of $\mathrm{H}-\mathrm{O}-\mathrm{H}$ is positioned at frequency $1630 \mathrm{~cm}^{-1}$ and the weak band of associated water is located at $2130 \mathrm{~cm}^{-1}$.

The identical spectra of the three specimens seem to indicate that the water molecules in the channels of natrolite are loosely bound to the framework and that the processes of dehydration and hydration and thermal treatment to which the mineral was subjected did not disrupt the bonds in the framework. The results are contrary to those of Yukhenevich et al (1961), who maintained 
that the dehydration of natrolite in the temperature range $130-160^{\circ} \mathrm{C}$ was accompanied by deformation of structure and that the mineral contained several types of water molecules differing from each other in bonding strength.

\section{Discussion and conclusions}

Contrary to the views of Milligan and Weiser (1937) and others, the dehydration of natrolite under vacuum conditions showed that water was lost continuously from the mineral and that there was no sign of other hydrates. The smoothness and absence of any discontinuity in the isobar indicates the structural equivalence of the water molecules in natrolite. At $189^{\circ} \mathrm{C}$ the fraction of water remaining in the mineral was 0.15 moles $\mathrm{H}_{2} \mathrm{O}$ per mole of $\mathrm{Na}_{2} \mathrm{Al}_{2} \mathrm{Si}_{3} \mathrm{O}_{10} \cdot 2 \mathrm{H}_{2} \mathrm{O}$. It is envisaged that very prolonged outgassing at this temperature might have expelled this fraction of water.

The isothermal experiments showed that the adsorptive capacity of the mineral was relatively high at the beginning of hydration, but it soon decreased as the amount of water entering the channels approached saturation. The rate at which equilibrium was established between the hydrated natrolite and water vapour indicates that the water molecules in natrolite are weakly bound. The degree of the bond strength may be correlated with the magnitude of the heat of hydration. Hey (1932b and 1935) argued that the large value of heat of hydration he obtained $\left(\triangle \mathrm{H}=23.300 \mathrm{Kcal} \cdot \mathrm{mole}^{-1} \mathrm{H}_{2} \mathrm{O}\right)$ proved that the water in natrolite is unlikely to be held by van der Waals forces but must be firmly attached to the framework. In this connection, Galwey (1967) had indicated that chemical bond formations are greater than $10 \mathrm{Kcal} \cdot \mathrm{mole}^{-1}$, but that in physical adsorption where residual forces occur between the adsorbed species and the solid, the heat of adsorption is low and is of the order of 4 Kcal.mole ${ }^{-1}$; though it may be higher when the molecule is adsorbed in a pore.

The results of the present investigation gave a value of $15.690 \mathrm{Kcal} . \mathrm{mole}^{-1} \mathrm{H}_{2} \mathrm{O}$ as the heat of hydration. This value may indicate that the water molecules in natrolite are chemically bound. But from the evidence revealed by the experiments outlined above, i.e. the fastness of hydration, the stability of the silicate framework in spite of cycles of dehydration-hydration and the continuous removal of water on heating, it is reasonable to suggest that natrolite is not a definite hydrate. Although no attempt was made in the current investigation to study the effect of dehydration on the cell dimensions of natrolite, the results obtained indicate that the absorption forces of the water molecules within the channels of the zeolite appear to be rather weak and that the crystal framework was not disrupted by thermal dehydration.

Acknowledgements. The author wishes to thank Dr. J. D. C. McConnell for his supervision, encouragement and advice during the progress of this research. Thanks are also due to Dr. S. O. Agrell for providing the specimen. The work was undertaken in the Department of Mineralogy and Petrology, Cambridge, during the tenure of a senior scholarship from the University of Khartown

\section{References}

Adler, H. H. (1955) Examination of mass/radius effects, hydrogen bonding in $\mathrm{V}_{\mathrm{b}}$ splitting in infrared spectra of $\mathrm{Zr}-\mathrm{Hf}$ homologues. Am. Mineral. 50, p. 132. 
Farmer, V. C. (1964) Infrared spectroscopy of silicates and related compounds. In the "Chemistry of Cement Vol: II, edited by H. F. W. Taylor, Academic Press, London, p. 289.

Fox, J. J. and Martin, A. E. (1940) Investigations of infrared spectra $(2.5-7.5 \mu)$ absorption of water. Proc. Roy. Soc. 174A, p. 234.

Galwey, A. K. (1967) Chemistry of solids, Science paperbacks. Chapt. 5, p. 163.

Hamad, S. el D. (1975) An experimental study of the salt hydrate $\mathrm{MgSO}_{4} \cdot 7 \mathrm{H}_{2} \mathrm{O}$. Thermochim. Acta 13: 409-418.

Hey, M. H. (1932b) Studies on the zeolites, Part III. Natrolite and metanatrolite. Mineral. Mag. 23 , p. 243.

Hey, M. H. (1935) Studies on the zeolites. Part VIII. A theory of the vapour pressure of the zeolites and of the diffusion of water or gases in a zeolite crystal. Mineral. Mag. 24, p. 99.

Mayer, A. A., Manuilova N. S., and Varshal B. G. (1964) Transformations of natrolite under hydrothermal conditions. Dokl. Acad. Sci. U.S.S.R., Earth Sci. Sec. 154, p. 89.

Milligan, W. C. and Weiser, H. B. (1937) The mechanism and dehydration of zeolites. J. Phys. Chem. 41, p. 1029.

Mitra, S. S. (1962) Vibration spectra of solids: Solid State Physics. Vol. 13, p.l.

Peng, C. J. (1955) Thermal analysis of the natrolite group. Am. Mineral. 40, p. 834.

Saha, P. (1961) The system $\mathrm{NaAlSiO}_{4}$ $\mathrm{NaAlSi}_{3} \mathrm{O}_{8}$. Am. Mineral 46, p. 859.

Serratosa, R. M. and Bradley W. F. (1958) Determination of the orientation of $\mathrm{OH}$ bond axes in layer silicates by infrared absorption. J. Phys. Chem., 62, p. 1164.

Yukhnevich, G. V., Karyakin A. V., Khitarov N. I. and Senderov E. E. (1961) Infrared spectroscopic study of some zeolites and the nature of the water bond in natrolite. Geochemistry, No. 10, p. 937 .

Manuscript received, April 30, 1976. 